\title{
UPAYA PENINGKATAN KOMPETENSI GURU MELALUI PEMANFAATAN APLIKASI GOOGLE FORM DI SEKOLAH DASAR
}

\author{
Susilo Tri Widodo ${ }^{1}$, Isa Ansori ${ }^{2}$, Ha. ZaenalAbidin ${ }^{3}$, Sigit Yulianto ${ }^{4}$, Suhardi ${ }^{5}$, \\ Noto Suharto ${ }^{6}$ \\ 1,2,3,4,5,6) Program Studi Pendidikan Guru Sekolah Dasar, Fakultas Ilmu Pendidikan, \\ Universitas Negeri Semarang \\ e-mail :susilotriwidodo@mail.unnes.ac.id
}

\begin{abstract}
Abstrak
Kegiatan pengabdian dilakukan bertujuan untuk meningkatkan soft skill guru dalam mengembangakan kompetensi memanfaatkan google form untuk media pembelajaran. Guru diberikan keahlian secara terbimbing dalam merancang media google form. Lokasi kegiatan pengabdian ini yaitu di SD Negeri Bringin 01, lama kegiatan ini direncanakan selama enam bulan. Hasil dari kegiatan pengabdian antara lain : penyampaian materi dari tim pengabdi terkait penggunaan aplikasi google form sebagai salah satu media pembelajaran. Para peserta sangat antusias dalam mengikuti kegiatan tersebut. Luaran dari kegiatan pengabdian ini berupa produk google form yang dihasilkan oleh peserta (guru SD). Luaran dari pengabdian ini berupa sampel desain porduk google form yang dikembangkan dan dihasilkan oleh peserta (guru SD), dan laporan pengabdian yang tidak dipublikasikan. Ada beberapa kendala yang dihadapi tim pengabdi yaitu penguasaan kemampuan komputer para guru yang belum merata sehingga hanya beberapa peserta tertentu yang mampu menyelesaikan produk media. Pengabdian ini mendapat respon yang positif dari para guru dan mereka sangat senang mendapatkan tambahan ilmu dalam mengembangkan media dan peningkatan kompetensi yang dimiliki.
\end{abstract}

Kata Kunci : Pelatihan, Media Pembelajaran, Google Form

\begin{abstract}
The devotional activities are aimed at improving the teacher's soft skills in developing competencies utilizing google forms for learning media. Teachers are given guided expertise in designing google form media. The location of this devotional activity is at BRINGIN 01 State Elementary School, the duration of this activity is planned for six months. The results of the devotional activities include: the delivery of materials from the service team related to the use of google form application as one of the learning media. The participants were very enthusiastic in participating in the activity. The exterior of this devotional activity is a google form product produced by participants (elementary school teachers). The exterior of this devotion is a sample of google form porduk design developed and produced by participants (elementary school teachers), and unpublished devotion reports. There are several obstacles faced by the service team, namely the mastery of computer skills of teachers that have not been evenly distributed so that only a few certain participants are able to complete media products. This devotion received a positive response from the teachers and they are very happy to get additional knowledge in developing the media and improving their competence.
\end{abstract}

Keywords : Training, Learning Media, Google Forms

\section{PENDAHULUAN}

Pendidikan di Indonesia secara dinamis semakin berkembang kearah yang lebih baik dan maju. Pengembangan pendidikan di Indonesia telah dilakukan dengan berbagai langkah dan upaya konkrit untuk mencapai tujuan bangsa Indonesia yaitu 
"mencerdasakan kehidupan bangsa". Untuk mencapai tujuan tersebut maka perlu regulasi implementatif sebagai tindak lanjut dalam pelaksanaannya. Undang-Undang No. 20 tahun 2003 tentang sistem pendidikan nasional merupakan payung hukum bagi pendidikan nasional Indonesia. Fungsi dari pendidikan nasional Indonesia dalam Undang-Undang tersebut yaitu pendidikan nasional Indonesia berfungsi untuk mengembangkan kemampuan dan membentuk watak serta peradaban bangsa yang bermartabat dalam rangka mencerdaskan kehidupan bangsa, dan bertujuan untuk berkembangnya potensi peserta didik agar menjadi manusia yang beriman dan bertakwa kepada Tuhan Yang Maha Esa, berakhlak mulia, sehat, berilmu, cakap, kreatif, mandiri, dan menjadi warga negara yang demokratis serta bertanggung jawab. Hal ini menunjukkan bahwa pendidikan sangat penting bagi bangsa ini, dalam rangka mewujudkan tujuan nasional Indonesia.

Pendidikan yang dikembangkan tidak akan lepas dengan adanya pengembangan kurikulum yang menjadi jantungnya pendidikan. Kurikulum dikembangkan berdasarkan kebutuhan dan tuntutan perkembangan dalam dunia pendidikan. Kurikulum sebagai dasar dalam pengembangan pembelajaran di sekolah. Pembelajaran merupakan suatu hal penting di dalam dunia pendidikan. Kegiatan pembelajaran selalu berhubungan dengan konsep belajar. Menurut Gagne (1984) dalam Martinis Yamin (2008 : 122), menyebutkan "Belajar sebagai suatu proses dimana organisme berubah perilakunya diakibatkan pengalaman". Hal itu dapat dimaknai bahwa belajar itu merupakan bagian dari sebuah pembelajaran. Menurut Rigeluth (1983) dalam Eveline Siregar dan Hartini Nara (2014 : 43). Teori pembelajaran ada dua yaitu teori preskriptif dan deskriptif, teori preskriptif adalah goal oriented sedangkan teori deskriptif adalah goal free. Hal tersebut dimaksudkan bahwa teori pembelajaran preskriptif berorientasi mencapai tujuan, sedangkan teori pembelajaran deskriptif dimaksudkan untuk memberikan hasil. Kegiatan pembelajaran yang seharusnya adalah pembelajaran yang efektif dan efisien, agar segala tujuan yang diharapkan dapat tercapai sehingga memberikan hasil yang diharapkan. Kegiatan pembelajaran yang bersifat kurang efektif dan kurang efisien, cenderung menghasilkan out put yang tidak sesuai dengan yang diharapakan.

Era disrupsi merupakan sebuah era yang penuh dengan perubahan secara cepat. Era disrupsi sebagai satu wujud perkembangan yang terjadi saat ini. Istilah disrupsi (disruption) secara bahasa menurut KKBI artinya halter cabut dari akarnya.Secara umum pemaknaan terhadap era disrupsi (disruption era) adalah era banyaknyaperubahan. Era disrupsi dipandang sebagai era semua orang berlomba menciptakan inovasi. Siapa yang tak berani berinovasi dan mengikuti zaman tersebut, pasti akan tertinggal.Inovasi dalam memanfaatkan teknologi menjadi hal penting sebagai bentuk jawaban terhadaptantangan era disrupsi saat ini. Seorang guru atau pendidik harus dapat mengembangkan pembelajaran yang efektif dan efisien. Untuk menghasilkan pembelajaran yang efektif dan efisien tersebut pastinya harus dapat mengembangkan berbagai komponen yang terkait dengan pembelajaran. Media pembelajaran merupakan salah satu komponen penting dalam mendukung proses pembelajaran agar tujuan pembelajaran yang diharapkan mudah tercapai.

Fakta yang ada dilapangan menunjukkan bahwa kompetensi guru yang dibangun memerlukan penguatan-pengutan dukungan melalui soft skill yang dimiliki. Terdapat 35 Sekolah Dasar di Kecamatan Ngaliyan, Kota Semarang, Propinsi Jawa Tengah baik negeri maupun swasta. Data Guru sampai dengan semester genap 2018/2019 menunjukkan terdapat 424 tenaga guru. Hasil observasi awal yang dilakukan oleh tim saat membimbing PPL di Sekolah Dasar, menunjukkan bahwa guru yang memanfaatkan teknologi komputer untuk mengembangkan media pembelajaran dikelas masih minim, hanya sekitar $20 \%$ saja yang memanfaatkan kemajuan teknologi untuk mengembangkan media pembelajaran di kelasnya masing-masing. Selain itu hasil diskusi tim dengan para guru menunjukkan bahwa mereka mengiginkan sebuah pelatihan dalam mengembangkan media pembelajaran yang berbasis dukungan teknologi. Hal ini mendorong tim untuk merencanakan memberikan pelatihan kepada guru-guru tersebut dengan menguatkan soft 
skill agar memiliki kemampuan berinovasi dalam pengembangan media pembelajaran berbasis teknologi yang dapat digunakan di kelasnya masing-masing. Selain itu identifikasi yang telah dilakukan oleh tim menunjukkan ada beberapa hal yang mendasari perlunya pelatihan ini dilaksanakan, antara lain : (1) Peningkatan kemampuan soft skill dalam mengembangkan media pembelajaran guru-guru sekolah dasar; (2) Inovasi terhadap media pembelajaran dengan melalui dukungan teknologi; dan (3) Peningkatan kompetensi merancang media dalam pembelajaran dalam menjawab tantangan di era disrupsi. Guru dapat berinovasi sesuai dengan kebutuhan dan tujuan pembelajaran yang ingin dicapai. Untuk merancang sebuah inovasi media pembelajaran memang memerlukan sebuah upaya yang terencana dan sistemik. Guru harus menyiapkannya dengan baik. Hal tersebut pastinya harus didukung dengan kemampuan soft skill dalam mengembangkan sebuah media pembelajaran.

Selain itu, hasil diskusi tim dengan mitra, ada beberapa hal permasalahan yang dihadapi mitra, antara lain :

1. Kemampuan pengembangan inovasi pembelajaran guru-guru di SD mitra masih perlu diberikan penguatan

2. Pemanfaatan teknologi dalam pengembangan pembelajaran di kelas

3. Penguatan kompetensi guru dalam pembelajaran.

Masalah konkret tersebut menjadi masukan tim pengabdi untuk merencanakan pengabdian dalam rangka mengatasi masalah yang dihadapi oleh mitra.Sesuai dengan keahlian tim pengabdi, maka tim merencankan untuk menyelesaikan permasalahan mitra dengan upaya yang konkret. Salah satu upaya yang direncanakan oleh tim pengabdi yaitu akan memanfaatkan media google form untuk mengembangkan kompetensi guru sekolah dasar. Kegiatan ini sejalan dengan rencana strategi LP2M Unnes di tahun 2020-2024, salah satunya inovasi pendidikan berkualitas dan berkarakter khusunya inovasi pembelajaran dalam bentuk pengembangan media pembelajaran.Identifikasi yang telah dilakukan oleh tim menunjukkan ada beberapa hal yang mendasari perlunya pelatihan ini dilaksanakan, antara lain :

1. Kemampuan pengembangan inovasi media pembelajaran guru-guru sekolah dasar masih perlu diberikan penguatan

2. Inovasi terhadap media pembelajaran dengan strategi yang lebihefektif

3. Peningkatankompetensi guru terutama soft skill pendukung kompetensi pedagogik dalam pembelajaran.

Berdasarkan identifikasi masalah di atas maka diperlukan sebuah pelatihan terbimbing dalam mengembangkan media pembelajaran inovatif. Untuk itu, maka tim memfokuskan dari kegiatan ini dalam sebuah rumusan masalah sebagai berikut : Bagaimana meningkatkan soft skill guru melalui pelatihan terbimbing membuat media pembelajaran melalui google form?

\section{METODE}

Metode yang diterapkan dalam pengabdian ini yaitu a) Pelatihan secara terbimbing pemnafaatan aplikasi google form kepada peserta, b) Pendampingan hingga menghasilkan media dengan google form untuk kelasnya masing-masing. Khalayak sasaran dalam pengabdian ini adalah guru kelas sekolah dasar SD N Bringin 01 dengan kriteria a) Memiliki kompetensi yang mendukung kompetensi pedagogik dan professional sebagai pendidik, b) Dipandang mampu mengikuti pelatihan dengan baik dan potensi menyebarluaskan keterampilannya kepada rekan guru yang lain. Kerangka pemecahan masalah yang direncanakan oleh tim pengabdi adalah sebagai berikut : 
Tabel 1 . Kerangka Pemecahan Masalah

\begin{tabular}{|c|c|c|}
\hline \multicolumn{2}{|r|}{ Indikator } & Target \\
\hline Input & $\begin{array}{l}\text { Guru kelas sejumlah } 10 \\
\text { orang }\end{array}$ & $\begin{array}{l}\text { Keikutsertaan } 10 \text { guru yang } \\
\text { ditunjuk dalam kegiatan pelatihan }\end{array}$ \\
\hline Output & $\begin{array}{l}10 \quad \text { guru mampu } \\
\text { mengembangkan media } \\
\text { menggunakan google form }\end{array}$ & $\begin{array}{l}10 \text { guru memiliki google form } \\
\text { untukmendukung pembelajaran di } \\
\text { kelas }\end{array}$ \\
\hline Outcome & $\begin{array}{l}\text { Peningkatan profesionalitas } \\
\text { guru }\end{array}$ & $\begin{array}{l}\text { Pemanfaatan media pembelajaran } \\
\text { menunjang kompetensiguru }\end{array}$ \\
\hline Benefit & Kreativitas guru & $\begin{array}{l}\text { Termotivasi untuk memanfatkan } \\
\text { aplikasi google form secara tepat } \\
\text { guna. }\end{array}$ \\
\hline Impact & Kompetensi guru & 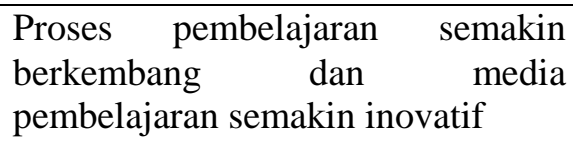 \\
\hline
\end{tabular}

Tabel 2. Realisasi dari pemecahan masalah sebagai berikut :

\begin{tabular}{|l|l|l|}
\hline \multicolumn{2}{|c|}{ Indikator } & \multicolumn{1}{|c|}{ Target } \\
\hline Input & $\begin{array}{l}\text { Guru kelas sejumlah 10 } \\
\text { orang }\end{array}$ & $\begin{array}{l}\text { Keikutsertaan 10 guru yang } \\
\text { ditunjuk dalam kegiatan pelatihan }\end{array}$ \\
\hline $\begin{array}{l}\text { Output } \\
\text { mengembangkan mampu media } \\
\text { menggunakan google form }\end{array}$ & $\begin{array}{l}10 \text { guru memiliki google form } \\
\text { untuk mendukung pembelajaran di } \\
\text { kelas }\end{array}$ \\
\hline Outcome & $\begin{array}{l}\text { Peningkatan profesionalitas } \\
\text { guru }\end{array}$ & $\begin{array}{l}\text { Pemanfaatan media pembelajaran } \\
\text { menunjang komptensi guru }\end{array}$ \\
\hline Benefit & Kreativitas guru & $\begin{array}{l}\text { Termotivasi untuk memanfatkan } \\
\text { aplikasi windosws movie maker } \\
\text { secara tepat guna. }\end{array}$ \\
\hline Impact & Kompetensi guru & $\begin{array}{l}\text { Proses pembelajaran semakin } \\
\text { berkembang dan media } \\
\text { pembelajaran semakin inovatif }\end{array}$ \\
\hline
\end{tabular}




\section{HASIL DAN PEMBAHASAN}

Program pengabdian masyarakat yang telah dilaksanakan oleh tim pengabdi mendapatkan beberapa hasil yang memberikan kontribusi besar kepada guru-guru sekolah dasar khususnya di SD Bringin 01. Kegiatan tersebut dirancang dengan melakukan berbagai aktivitas sebagai berikut :

1. Penyusunan Materi Kegiatan: Materi disusun oleh tim pengabdi sesuai dengan judul yang telah dirancang. Materi disusun dalam bentuk power point sehingga harapan dari tim pengabdi materi mudah untuk dapat dimengerti oleh peserta. Materi bersifat teknis artinya lebih mengarahkan kepada peserta untuk dapat merancang menggunakan aplikasi movie maker secara mudah.

2. Perijinan Pengabdian :Perijinan pengabdian dilakukan sesuai dengan prosedur yang ditentukan oleh aturan yang berlaku. Perijinan menyesuaikan lokasi yang akan digunakan. Proses perijinan ini, tim pengabdi tidak mengalami kendala, pihak mitra sangat senang apabila digunakan sebagai tempat pelaksanaan program pengabdian masyarakat.

3. Koordinasi dengan mitra pengabdian :Koordinasi dengan mitra dilakukan oleh tim pengabdi untuk menentukan kesepakatan perencanaan waktu pengabdian. Koordinasi dilakukan oleh tim pengabdi dengan Kepala Sekolah SD Negeri Bringin 01 diperoleh kesepakatan kegiatan dilakukan tanggal 14 Oktober 2020.

4. Pelaksanaan Kegiatan :Kegiatan yang dilaksanakan dihadiri oleh 12 peserta yaitu guru-guru SDNegeri Bringin 01, dan mahasiswa yang ikut terlibat. Kegiatan Pada tanggal 14 Oktober 2020 dilakukan penyampaian materi dari tim pengabdi terkait pemanfaatan aplikasi google form dan perancangan media dengan aplikasi tersebut. Ada beberapa kendala yang dihadapi tim pengabdi yaitu penguasaan kemampuan komputer para guru yang belum merata sehingga hanya beberapa peserta tertentu yang mampu menyelesaikan produk media. Kendala tersebut sudah diantisipasi oleh tim pengabdi dengan melibatkan mahasiswa yang mengerti komputer dan internet kita libatkan dalam kegiatan pengabdian untuk mendampingi peserta pelatihan.

Kegiatan pengabdian masyarakat tersebut sebagai bentuk nyata dukungan kepada para guru Sekolah Dasar dalam pengembangan media pembelajaran yang berbasis teknologi yang berkembang saat sekarang ini. Apabila merujuk pendapat Azhar Arsyad (2014: 3) yang menyebutkan bahwa media secara etimologis berasal dari kata medius yang berarti tengah, perantara, atau pengantar dan menurut Criticos dalam Daryanto (2013 : 5) yang mengatakan media merupakan salah satu komponen komunikasi yaitu sebagai pembawa pesan dari komunikator menuju komunikan, telah jelas bahwa dengan pemanfaatan aplikasi mind map sebagai media pembelajaran seharusnya dapat memberikan nilai positif dan mendorong proses pembelajaran semakin lebih efektif. Hal tersebut akan dibuktikan oleh guru-guru peserta program pengabdian ini.Pengembangan media menggunakanaplikasi google form sangat mudah dilakukan, banyak peserta guru yang berupaya mencoba merancang secara sederhana. Hal ini menjadi bagian penting dalam mengembangkan kompetensi seorang guru untuk merancang dan mengembangkan media yang berbasis teknologi yang dapat digunakan untuk meningkatkan kualitas pembelajaran di kelas masing-masing.

\section{SIMPULAN}

Berdasarkan deskripsi hasil yang dicapai maka dapat diambil kesimpulan sebagai berikut : Pengabdian dapat terlaksana jika terjalin kerjasama yang baik dengan mitra, Pengabdian akan dilaksanakan sesuai waktu yang telah disepakati. Target yang direncanakan oleh tim pengabdi dapat berhasil sesuai rencana. 


\section{SARAN}

Saran yang diberikan oleh pengabdi yaitu :Peningkatan kompetensi guru dilakukan secara kontiniu untuk menguatkan kapasitas yang dimiliki, Pengembangan media pembelajaran yang sesuai dengan kebutuhan peserta didik di sekolah dasar, Pemanfaatan aplikasi google form mendorong peningkatan kompetensiguru dalam mengembangkan media pembelajaran.

\section{UCAPAN TERIMAKASIH}

Tim pengabdi mengucapkan terima kasih kepada civitas akademika Fakultas Ilmu Pendidikan, Universitas Negeri Semarang yang telah memberikan dukungan dana dalam kegiatan pengabdian ini.

\section{DAFTAR PUSTAKA}

Anitah, Sri. (2014). Teknologi Pembelajaran. Surakarta : Learning Resources Center FKIP UNS

--. (2015). Strategi Pembelajaran di SD. Jakarta : UT Press

Clark, John dan Ken Guy. (1997). Innovation and Competitiveness. Technopolis. July 1997

Etherington, Darrell. (2014). Google Debuts Classroom, An Education Platform For Teacher-Student Communication. TechCrunch. Diakses tanggal 2 Maret 2020

Joni, TR. (2015). Strategi Belajar Mengajar. Jakarta. Kemendikbud

Magid, Larry. (2014). Google Classroom Offers Assignment Center for Students and Teachers. Forbes. Diakses tanggal 2 Maret 2020.

Perez, Sarah. (2015). Google Expands Its Educational Platform "Classroom" With A New API, Share Button For Websites. TechCrunch. AOL Inc. Diakses tanggal 2 Maret 2020

Sanjaya, Wina. (2010). Perencanaan dan Desain Sistem Pembelajaran. Jakarta: Kencana Prenada Media Group

Silberman, Mel. (2002). Active learning : 101 Strategi Pembelajaran Aktif. Yogyakarta : Yappendis.

Siregar, Eveline dan Nara, Hartini. (2014). Teori Belajar dan Pembelajaran. Bogor : Ghalia Indonesia

Sudiarto. (2010). Strategi Pembelajaran. Jakarta : Dikti

Yamin, Martinis. (2008). Paradigma Pendidikan Konstruktivistik. Jakarta : Gaung Persada Press. 